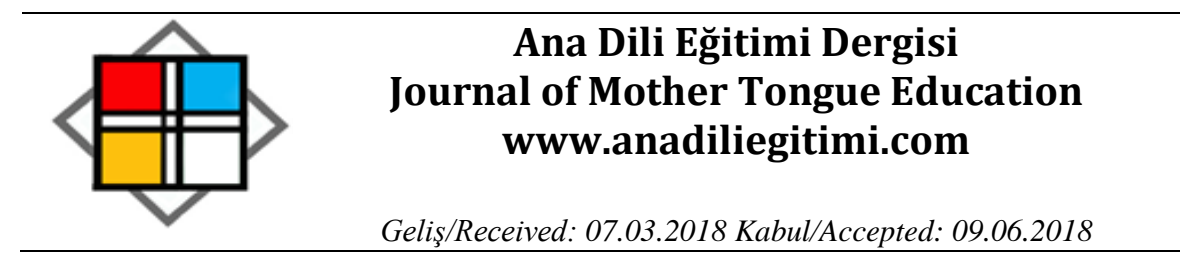

\title{
Türkçeyi Yabancı Dil Olarak Öğretenlerin Öz Yeterlik Algılarının İncelenmesi*
}

\begin{abstract}
Kübra ŞENGÜL**
Öz

Bu araştırmanın amacı, Türkçeyi yabancı dil olarak öğretenlerin öz yeterlik algılarını cinsiyet, yaş, mezun olunan lisans programı, öğrenim düzeyi ve deneyim süresine göre incelemektir. Araştırmada Nicel Yaklaşımlardan Kesitsel Tarama Yöntemi kullanılmıştır. Veri toplama aracı olarak, Tschannen-Moran ve Woolfolk Hoy tarafından 2001 yılında geliştirilen; Çapa, Çakıroğlu ve Sarıkaya (2005) tarafından Türkçeye uyarlanan “Öğretmen Öz Yeterlik Ölçeği” kullanılmıştır. 24 maddeden oluşan ölçek üç boyuttan oluşmaktadır. Bunlar; öğrenci katılımına yönelik öz yeterlik, öğretim stratejilerine yönelik öz yeterlik ve sınıf yönetimine yönelik öz yeterliktir. Araştırmada; Atatürk, Aydın, Dokuz Eylül, Gazi, Nevşehir Hacı Bektaş Veli, Uludağ Üniversiteleri, Yunus Emre Enstitüsü ve Ankara ile İstanbul'daki özel kurslarda Türkçeyi yabancı dil olarak öğreten 118 kişiye ulaşılmıştır. Araştırmada, Türkçeyi yabancı dil olarak öğretenlerin öz yeterlik algılarının cinsiyetlerine ve yaşlarına göre anlamlı düzeyde farklılaşmadığı ancak mezun olunan lisans programı, öğrenim düzeyi ve deneyim süresine göre anlamlı düzeyde farklılaştığı sonucuna ulaşılmıştır.
\end{abstract}

Anahtar Kelimeler: Öz yeterlik algısı, öğretmen öz yeterliği, yabancı dil olarak Türkçe öğretimi

\section{Self-Efficacy Perceptions of Teachers who teach Turkish as a Foreign Language}

\begin{abstract}
The purpose of this research is to examine the self-efficacy perceptions of teachers who teach Turkish as a foreign language in terms of gender, age, undergraduate major, level of education and experience. Cross-sectional survey which is one of the quantitative research methods was used in this study. As the data collection tool, the "Teacher Self-Efficacy Scale", developed by Tschannen-Moran and Woolfolk Hoy (2001) and adapted by Çapı, Çakıroğlu and Sarıkaya (2005), was used. The scale which consists of 24 items has three dimensions. These are self-efficacy for student participation, self-efficacy for teaching strategies and self-efficacy for classroom management. The participants in this study were 118 teachers who taught Turkish as a foreign language at the universities of Atatürk, Aydın, Dokuz Eylül, Gazi, Nevşehir Hacı Bektaş Veli, and Uludağ, the Yunus Emre Institute, and private teaching institutions in Ankara and İstanbul. In the study, the self-efficacy perceptions of teachers did not differ significantly in terms of gender and age, but meaningful differences appeared in terms of teachers' undergraduate major, level of education and experience.
\end{abstract}

Keywords: Self-efficacy perception, Teacher self-efficacy, Teaching Turkish as a foreign language

*17-19 Mayıs 2017 tarihlerinde Bursa'da düzenlenen I. Uluslararası Yabancı Dil Olarak Türkçenin Öğretimi Bilgi Şöleninde sözlü bildiri olarak sunulmuştur.

${ }^{* *}$ Dr. Öğr. Ü.. Nevşehir Hacı Bektaş Veli Üniversitesi Eğitim Fakültesi Türkçe Eğitimi Anabilim Dalı, kubraturkersengul@gmail.com 


\section{Giriş}

Öğrenmenin doğası üzerine yapılan çalışmalar davranışçı öğrenme yaklaşımdan (Klasik Koşullanma, Edimsel Koşullanma, Bitişiklik, Bağlaşımcılık Kuramı) davranış̧̧ı ve bilişsel yaklaşımlar arasında kalan öğrenme modellerine (Sosyal Öğrenme, İşaret Gestalt Kuramı) ve son olarak bilişsel öğrenme yaklaşımlarının vurguladığı (Sosyal Bilişsel Öğrenme Kuramı, Bilgi İşleme Kuramı, Gestalt Kuramı) kuramlara doğru yön kazanmıştır. Bandura'nın 1960'lı yıllarda yaptığı araştırmalar (Bandura, ve Huston, 1961; Bandura, Ross ve Ross, 1963; Bandura, 1965) çocukların filmlerde geçen ya da doğrudan gösterilen rol modellerin yaşantılarının sonuçlarından etkilenerek öğrenebildiğini göstermiştir. Böylelikle Bandura, birey, çevre ve davranış faktörlerine dayalı olan Sosyal Bilişsel Öğrenme Kuramını geliştirmiştir. Bu kurama göre birey, sosyal çevresinde yaşanan olayları gözlemleyerek dolaylı yaşantılar yolu ile öğrenme sürecine girmektedir. Bandura'nın Sosyal Bilişsel Öğrenme Kuramında temelini attı̆̆ı; dolaylı pekiştirme, dolaylı ceza, dolaylı duygu, dolaylı güdülenme, model özellikleri, karşılıklı belirleyicilik, öngörü, sembolleştirme, dolaylı öğrenme, öz yargılama kapasitesi, öz düzenleme ve öz yeterlik gibi bazı ilke ve kavramlar öğrenme psikolojisinde güçlü bir şekilde yerini almıştır. Sosyal Bilişsel Öğrenme Kuramının belirttiği bu ilke ve kavramlar, hem davranış̧ı yaklaşımın iddia ettiği basit düzeydeki uyarıcı tepki bağının insan öğrenmelerini açıklayamayacağını hem de doğrudan yaşantıların söz konusu olmadığı durumlarda bireyin bilişsel etkinliklerle öğrenme sürecine girebileceğini belirtmiştir. Sosyal Bilişsel Öğrenme Kuramının vurguladığı bir diğer kavram da öz yeterlik algısıdır. Bandura'ya (1982) göre bireyin, öğrenme gerçekleştirebilmede, öz yeterlik algısı yani bireyin davranışı yapabileceğine dair kendisine ilişkin algısı büyük öneme sahiptir.

\section{Öz Yeterlik}

Öz yeterlik kavramını, Bandura (2001) bireyin belli bir davranışı göstermek için gerekli işleri düzenleyip başarılı bir şekilde yapma durumuna ilişkin kendi yargısı olarak tanımlamaktadır. Bireyler öz yeterlik algılarını göreve yönelik kendi tecrübelerinden, dolaylı yaşantılardan, çevrenin bireye yönlendirdiği sözel iknalardan ve psikolojik durumlarından etkilenerek oluşturmaktadır (Bandura, 1982; Schunk, 1987). "Algılanan öz yeterlik, bireyin göreve yaklaşımını ve performansın sonuçlarını etkilediğinden göreve yönelik motivasyon derecesini de etkilemektedir" (Bandura, 1999, s. 28). Bireyin göreve yönelik gerçekleştirdiği geçmiş başarıları, görevi başarmaya yönelik öz yeterlik algısını beslerken, çevrenin bu görevi yapabileceğine dair teşvikleri ve bireyin kendi psikolojik durumu (cesaret, öz güven vb.) öz yeterlik algılarını güçlendirmektedir. Bandura (1982), öz yeterlik algısının bireyin göreve yönelik göstereceği sebatı da etkilediğini vurgulamaktadır. 
Algılanan öz-yeterlik, Sosyal Bilişsel Öğrenme Kuramında merkezi bir rol oynamaktadır. Çünkü yeterlik algısı, sadece ilgili davranışın sonucunu değil aynı zamanda diğer değişkenler üzerindeki isteği, analitik ve stratejik düşünmeyi, olumsuzluklara karşı direnci ve motivasyonu da etkilemektedir (Bandura, 1999; Bandura, Barbaranelli, Caprara, ve Pastorelli, 2001). Dolayısıyla bireyin sahip olduğu öz yeterlik algısı onun davranışlarına yön vermekle kalmamakta aynı zamanda farklı görevlere ilişkin kararlarını da etkilemektedir (Bandura, 1999).

\section{Öğretmen Öz Yeterliği}

Öğretmen yeterliklerine ilişkin çalışmaların ilk olarak 70'li yıllarda Rotter'ın (1966) çalışmalarını teorik bir temel olarak alan RAND araştırmacıları tarafından yapıldığı görülmektedir (Tschannen-Moran, Woolfolk Hoy ve Hoy, 1998). Bu araştırmalarda, motive olmayan öğrencilerin bile öğrenmelerini daha iyi etkileyebileceğine dair öğretmenlerin geliştirdikleri inanç ya da kanaatler, öğretmen yeterlik algısı olarak tanımlanmıştır (Tschannen-Moran, Woolfolk Hoy ve Hoy, 1998). Daha genel anlamda öğretmenin, öğretim sürecindeki görevlerle baş edebileceğine ilişkin kendisine yönelik algısına öğretmen öz yeterliği denmektedir Öğretmen öz yeterliği, öğretim sürecinde öğrencileri etkinliğe yönlendirmede, öğretim stratejilerini kullanmada ve sınıf yönetimini sağlamada kendilerini nasıl algıladıklarına işaret ettiğinden öğretmen yetiştirme araştırmalarının merkez konularından da biri olmuştur. Bilişsel yaklaşımın etkisiyle öğrenci rolünün değişmesi, öğretmenin sınıf içindeki konumunun da değişmesini, böylelikle öğretmenin taşıması gereken yeterliklerin belirlenmesini sağlamıştır. Bu doğrultuda öğretim sürecinin önemli bir ögesini oluşturan öğretmenlerin performanslarının değerlendirilmesinde öz yeterlik algılarının araştırıldığı çalışmalar önem kazanmıştır.

Öğretmen yetiştirme alanında öğretmen adaylarının (Ekinci, 2013; Demirtaş, Cömert ve Özer, 2011; Şahin, Kurudayıoğlu, Tunçel ve Öztürk, 2013; Yaylı ve Kitiş Çınar, 2015; Ülper ve Bağcı, 2012) ve kurum içindeki öğretmenlerin (Korkut ve Babaoğlan 2012; Saracaloğlu, Karasakaloğlu, Evin Gencel, 2010; Üstüner, Demirtaş, Cömert ve Özer, 2009) öz yeterlik algılarının araştıııldığı çalışmalarda öğretmenlerin öz yeterlik algıları ile ilişkisi bulunan ögeler tespit edilmeye çalışımıştır. Örneğin, Ülper ve Bağcı (2012), çalışmalarında, Türkçe öğretmeni adaylarının öz yeterlik algılarının, başarı notu yüksek olanların lehine anlamlı oranda farklılık gösterdiğini tespit etmişlerdir. Buna benzer olarak Fackler ve Malmberg (2016), öğretmen öz yeterlik algısı ile öğrencinin öğrenme başarısı arasında pozitif bir ilişki olduğunu tespit etmişlerdir. Üstüner, Demirtaş, Cömert ve Özer'in (2009) yaptıkları araştırmada da Anadolu ve Fen Liselerinde çalışan öğretmenlerin öz yeterlik algıları, normal liselerde çalışan öğretmenlere göre anlamlı oranda yüksek çıkmıştır. Alan yazında yapılan bu araştırmalarda elde edilen sonuçlar, başarı ile öz yeterlik algısında pozitif bir ilişki olduğunu göstermektedir. Bu durum, hem bireyin kendi başarısı ile öz yeterlik algısı hem de öğrencisinin başarısı ile öğretmenin öz 
yeterlik algısı arasındaki ilişki için geçerlidir. Harrison, Rainer, Hochwarter ve Thompson (1997) da öz yeterlik algısı ile gösterilen performans arasında yüksek bir ilişkinin olduğunu tespit etmişlerdir.

Yaylı ve Kitiş Çınar (2015), Türkçe öğretmeni adaylarının öz yeterlik algılarını boylamsal bir yöntemle inceledikleri çalışmalarında, Türkçe öğretmeni adaylarının öz yeterlik algılarının genel anlamda ve tüm alt boyutlarda anlamlı bir şekilde yükseldiğini, böylelikle lisans eğitiminin öz yeterlik algısını olumlu yönde etkilediğini tespit etmişlerdir. Şahin, Kurudayıoğlu, Tunçel ve Öztürk (2013), yabancılara Türkçe öğretimi dersini alan öğretmen adaylarının yabancılara Türkçe öğretimine yönelik öz yeterlik algılarını inceledikleri çalışmada 4. sınıf öğrencilerinin yöntem bilgisi değişkenine göre daha yüksek öz yeterlik algısına sahip olduklarını belirlemişlerdir. Bu çalışmalar alınan eğitimin öğretmen adaylarının öz yeterlik algılarını olumlu yönde etkilediğini göstermektedir. Benzer olarak Yoo (2016), 5 haftalık çevrimiçi mesleki gelişim programını alan öğretmenlerin öz yeterlik algılarının anlamlı oranda yükseldiğini belirlemiştir.

Alan yazınında çeşitli branş öğretmenlerine yönelik yeterlik algısı çalışmalarının 20. yüzyıldan itibaren yapıldığı görülmektedir. Ancak Türkçeyi yabancı dil olarak öğretenlerin yeterlikleri ile yeterlik algılarına ilişkin araştırmalar, 2000'li yıllarla birlikte başlamıştır. Kalkınma Bakanlığının (2015) verilerine göre Türkiye'ye gelen yabancı öğrenci sayısı 2003 yılından itibaren her geçen yıl artış göstermektedir. Bu gelişmeler aynı zamanda çeşitli kurum ve kuruluşlar altında Türkçenin yabancı dil olarak öğretimine ilişkin faaliyetlerin artış göstermesini de sağlamıştır. Böylelikle alan yazınında yabancı dil olarak Türkçe öğretiminde öğretmen yeterliklerine yönelik çalışmaların (Alyılmaz, 2010; Barın, 2010; Barın, Çangal ve Başar 2017; Karababa, 2009; Mete, 2012; Mete ve Gürsoy, 2013; Şengül, 2015; Yıldız ve Tepeli, 2014) öneminin arttığı görülmektedir. Öğretmen yetiştirme boyutunun Türkçeyi yabancı dil olarak öğretmeye yönelik yeterlikler çerçevesinde ele alınmasıyla birlikte hâlihazırda Türkçeyi yabancı dil olarak öğretenlerin sahip oldukları yeterlik algılarının incelenmesi alan yazında önemli bir araştırma konusu olmuştur.

\section{Araştırmanın Amacı}

Bu araştırmanın amacı, Türkçeyi yabancı dil olarak öğretenlerin öz yeterlik algılarını cinsiyet, yaş, mezun olunan lisans programı, öğrenim düzeyi ve deneyim süresine göre incelemektir. Bu amaçla çalışmada şu sorulara cevap aranmıştır.

1- Türkçeyi yabancı dil olarak öğretenlerin öz yeterlik algıları cinsiyetlerine göre anlamlı düzeyde farklılaşmakta mıdır?

2- Türkçeyi yabancı dil olarak öğretenlerin öz yeterlik algıları yaşlarına göre anlamlı düzeyde farklılaşmakta mıdır? 
3- Türkçeyi yabancı dil olarak öğretenlerin öz yeterlik algıları mezun olunan lisans programına göre anlamlı düzeyde farklılaşmakta mıdır?

4- Türkçeyi yabancı dil olarak öğretenlerin öz yeterlik algıları öğrenim düzeyine göre anlamlı düzeyde farklılaşmakta mıdır?

5- Türkçeyi yabancı dil olarak öğretenlerin öz yeterlik algıları deneyim süresine göre anlamlı düzeyde farklılaşmakta mıdır?

\section{Yöntem}

\section{Araştırmanın Modeli}

Araştırmada Nicel Yaklaşımlardan Kesitsel Tarama Yöntemi kullanılmıştır. "Tarama yöntemi genel olarak bir evrenin kendine has özelliklerini anlayabilmek için yürütülen bilimsel araştırma yöntemidir" (Johnson and Christensen, 2000'den aktaran Özdemir, 2015, s. 79). Tarama araştırmalarında genelleme yapmak esastır. "Herhangi bir olguyu tanımlamak için onun hakkında pek çok bilgi edinmek gerektiğinden tarama araştırmaları, genellikle çok fazla miktarda veriye dayalı olarak gerçekleştirilir" (Özdemir, 2015, s. 79). Tarama Yönteminin çeşitli türleri bulunmaktadır. Bunlar; kesitsel, boylamsal ve geçmişe dönüktür (Büyüköztürk, Kılıç - Çakmak, Akgün, Karadeniz, Demirel, 2014). Bu araştırmada Türkçeyi yabancı dil olarak öğretenlerin öz yeterlik algılarına ilişkin veriler tek seferde toplandığı için çalışma, Kesitsel Tarama Yönteminin bir örneğini temsil etmektedir.

\section{Örneklem}

Araştırmada en fazla sayıda örnekleme ulaşılmak amaçlandığı için Seçkisiz Örnekleme Yöntemlerinden Basit Seçkisiz Örnekleme Yöntemi kullanılmıştır. Basit Seçkisiz Örnekleme Yönteminin en belirgin özelliği, evrendekilerin araştırma sürecine dâhil olabilmek için her birinin eşit ve bağımsız bir şansa sahip olmasıdır (Ekiz, 2013). "Basit Seçkisiz Örnekleme Yöntemi, temsil edici bir örneklem seçiminin geçerli ve en iyi yoludur" (Büyüköztürk, vd., 2014, s. 177).

Araştırmada. Atatürk, Aydın, Dokuz Eylül, Gazi, Nevşehir Hacı Bektaş Veli, Uludağ Üniversiteleri, Yunus Emre Enstitüsü ve Ankara ile İstanbul'daki özel kurslarda Türkçeyi yabancı dil olarak öğreten 118 kişiye ulaşıımıştır. Örneklemin cinsiyet, yaş, mezun olunan lisans programı, öğrenim düzeyi ve deneyim süresine ilişkin frekans ve yüzdelik değerlerini göstermek için pasta grafiği kullanılmıştır. 


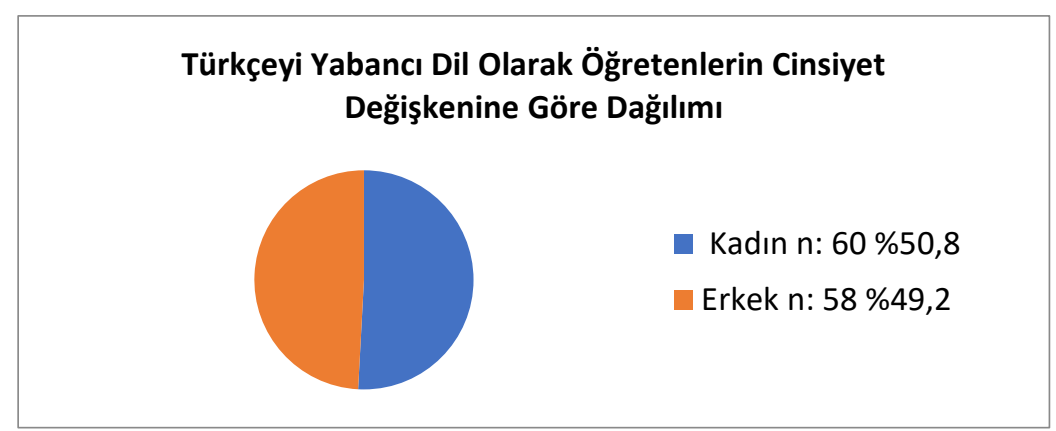

Grafik 1. Türkçeyi yabancı dil olarak öğretenlerin cinsiyet değişkenine göre dağılımı

Grafik 1 incelendiğinde Türkçeyi yabancı dil olarak öğreten kadın ( $n=60)$ ve erkek $(n=58)$ sayılarının oranlı bir dağılıma sahip olduğu görülmektedir.

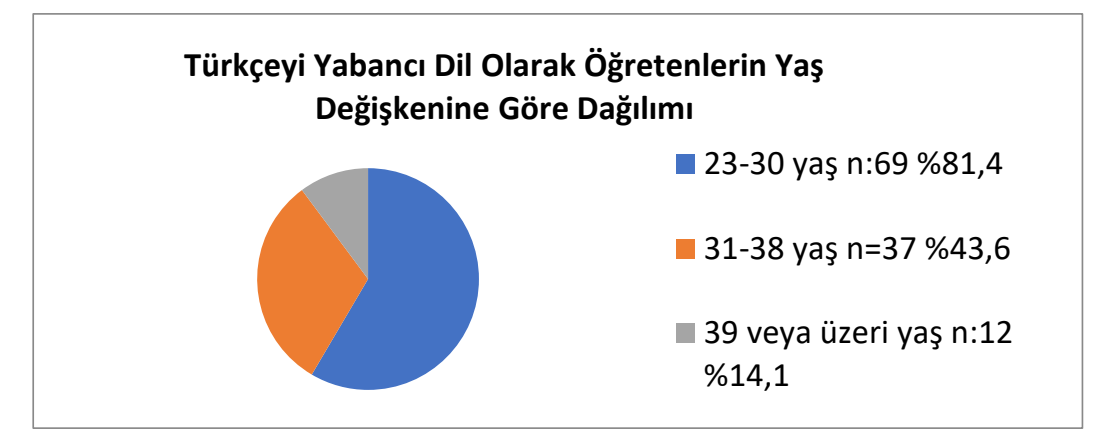

Grafik 2. Türkçeyi yabancı dil olarak öğretenlerin yaş değişkenine göre dağıımı

Grafik 2 incelendiğinde, Türkçeyi yabancı dil olarak öğretenlerin en çok 23-30 yaş grubunda daha sonra ise 31-38 yaş grubunda olduğu görülmektedir. Bu da Türkçeyi yabancı dil olarak öğretenlerin genç bir kesimden oluştuğunu göstermektedir.

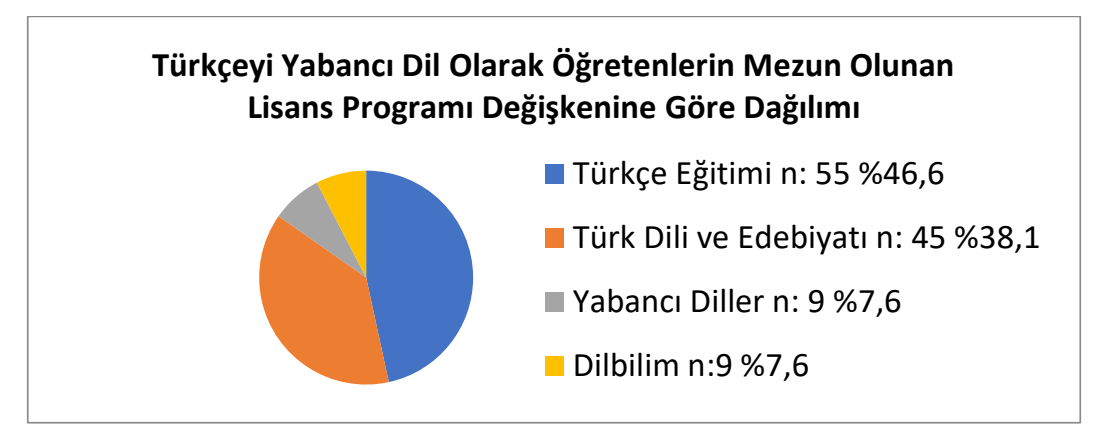

Grafik 3. Türkçeyi yabancı dil olarak öğretenlerin mezun olunan lisans değişkenine göre dağııımı

Türkçeyi yabancı dil olarak öğretenlerin mezun olunan lisans programı değişkenine göre dağılımlarına bakıldığında en çok Türkçe Eğitimi mezunlarının daha sonra ise Türk Dili ve Edebiyatı mezunlarının görev yaptığı görülmektedir. 


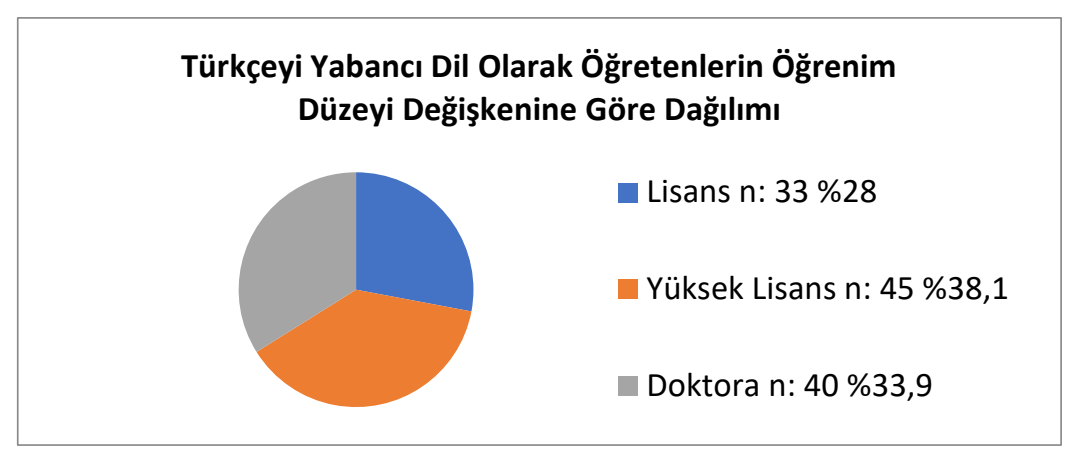

Grafik 4. Türkçeyi yabancı dil olarak öğretenlerin mezun olunan lisans değişkenine göre dağılımı

Türkçeyi yabancı dil olarak öğretenlerin öğrenim düzeyi değişkenine göre dağılımlarına bakıldığında ise lisans, yüksek lisans ve doktora öğrenim düzeyindekilerin oranlı bir dağılımda oldukları ancak en çok yüksek lisans düzeyinde daha sonra doktora düzeyinde öğrenim düzeyine sahip oldukları görülmektedir. Bu da Türkçeyi yabancı dil olarak öğretenlerin uzman bir kesim tarafından yürütüldüğünü göstermektedir.

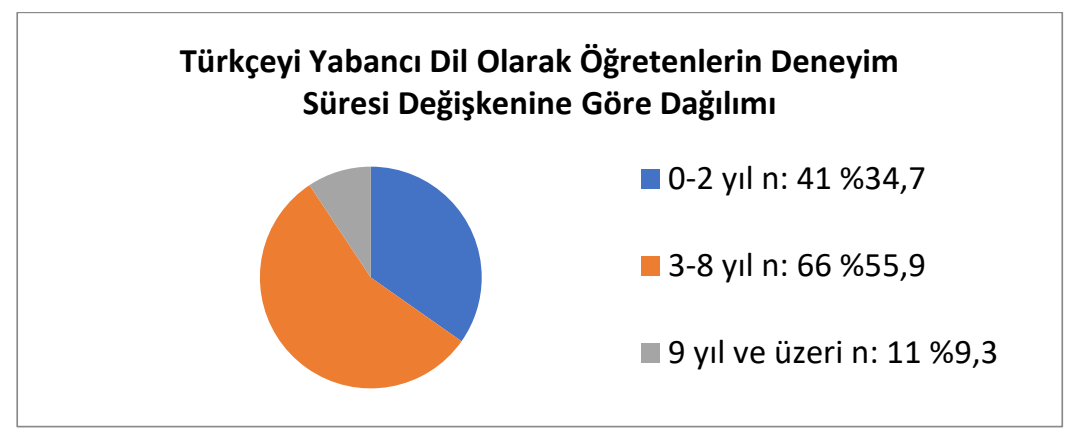

Grafik 5. Türkçeyi yabancı dil olarak öğretenlerin deneyim süresi değişkenine göre dağılımı

Grafik 5'te Türkçeyi yabancı dil olarak öğretenlerin en çok 3-8 yıl arasında ardından 0-2 yıl arasında deneyimli oldukları görülmektedir. Dolayısıyla Türkçeyi yabancı dil olarak öğretenlerin çoğunun $(\% 55,9)$ orta düzeyde bir deneyime sahip olduğu söylenebilir.

\section{Veri Toplama Araçları}

Veri toplama aracı olarak, Tschannen-Moran ve Woolfolk Hoy'ın 2001 yılında geliştirdikleri; Çapa, Çakıroğlu ve Sarıkaya'nın (2005) Türkçeye uyarladıkları “Öğretmen Öz Yeterlik Ölçeği” ve değişkenlerin yüzde ve frekans değerlerini saptamak için kişisel bilgi belgesi kullanılmıştır. Ölçek, öğrenci katılımına yönelik öz yeterlik, öğretim stratejilerine yönelik öz yeterlik ve sınıf yönetimine yönelik öz yeterlik alt boyutlarında toplam 24 maddeden oluşmaktadır. Alan yazın incelendiğinde bu ölçeğin pek çok çalışmada kullanıldığı görülmektedir (Demirtaş, Cömert ve Özer, 2011; Kavrayıcı ve Bayrak, 2016; Saracaloğlu, Karasakloğlu ve Evin-Gencel, 2010; Üstüner, Demirtaş, Cömert ve Özer, 2009; Üstün ve Tekin, 2009). 


\section{Verilerin Analizi}

Verilerin analizinde frekans, yüzde, Levene Homojenlik Testinde homojen çıkan gruplar için Bağımsız Gruplar t-Testi ve Levene Homojenlik Testinde homojen çıkmayan gruplar için Kruskal-Wallis H Testi kullanılmıştır.

\section{Bulgular}

"Türkçeyi yabancı dil olarak öğretenlerin öz yeterlik algıları cinsiyetlerine göre anlamlı düzeyde farklılaşmakta mıdır?" sorusuna ilişkin bulgular Tablo 1'de gösterilmektedir.

Tablo 1. Türkçeyi yabancı dil olarak öğretenlerin öz yeterlik ölçeği puanlarının cinsiyet değişkenine göre Bağımsız Gruplar t-Testi sonuçları

\begin{tabular}{|c|c|c|c|c|c|c|c|c|}
\hline \multirow{2}{*}{ Faktörler } & \multirow{2}{*}{ Cinsiyet } & \multirow{2}{*}{$\mathbf{N}$} & \multirow{2}{*}{$\overline{\mathbf{X}}$} & \multirow{2}{*}{ SS } & \multicolumn{2}{|c|}{ Levene } & \multirow{2}{*}{$\mathbf{t}$} & \multirow{2}{*}{$\mathbf{P}$} \\
\hline & & & & & $\mathbf{F}$ & $\mathbf{p}$ & & \\
\hline \multirow{2}{*}{$\begin{array}{l}\text { Öğrenci katılımına } \\
\text { yönelik öz yeterlik }\end{array}$} & Kadın & 60 & 6,77 & 1,73 & \multirow{2}{*}{2,71} & \multirow{2}{*}{0,10} & \multirow{2}{*}{$-0,70$} & \multirow{2}{*}{$0,48^{*}$} \\
\hline & Erkek & 58 & 6,97 & 1,43 & & & & \\
\hline \multirow{2}{*}{$\begin{array}{l}\text { Öğretim stratejilerine } \\
\text { yönelik öz yeterlik }\end{array}$} & Kadın & 60 & 7,12 & 1,76 & \multirow{2}{*}{2,70} & \multirow{2}{*}{0,10} & \multirow{2}{*}{$-1,16$} & \multirow{2}{*}{$0,24^{*}$} \\
\hline & Erkek & 58 & 7,47 & 1,48 & & & & \\
\hline \multicolumn{2}{|c|}{ Sınıf yönetimine yönelik Kadın } & 60 & 7,29 & 1,42 & \multirow{2}{*}{2,57} & \multirow{2}{*}{0,11} & \multirow{2}{*}{$-1,60$} & \multirow{2}{*}{$0,11^{*}$} \\
\hline öz yeterlik & Erkek & 58 & 7,68 & 1,25 & & & & \\
\hline
\end{tabular}

${ }^{*} \mathrm{p}>0,05$

Tablo 1 incelendiğinde Türkçeyi yabancı dil olarak öğretenlerin öz yeterlik algılarının cinsiyet değişkeninde ölçeğin üç alt boyutunda da anlamlı bir farklılık oluşturmadığı görülmektedir. Elde edilen bu bulgular alan yazındaki (Ekinci, 2013; Üstüner, Demirtaş, Cömert ve Özer, 2009) diğer çalışmaların sonuçlarıyla da örtüşmektedir.

"Türkçeyi yabancı dil olarak öğretenlerin öz yeterlik algıları yaşlarına göre anlamlı düzeyde farklılaşmakta mıdır?" sorusuna ilişkin bulgular Tablo 2'de gösterilmektedir.

Tablo 2. Türkçeyi yabancı dil olarak öğretenlerin öz yeterlik ölçeği puanlarının yaş değişkenine göre KruskalWallis H Testi sonuçları

\begin{tabular}{|c|c|c|c|c|c|}
\hline Faktörler & Gruplar & $\mathbf{N}$ & Sıra Ortalaması & KWH & $\mathbf{P}$ \\
\hline \multirow{3}{*}{$\begin{array}{l}\text { Öğrenci katılımına yönelik } \\
\text { öz yeterlik }\end{array}$} & 23-30 yaş & 69 & 59,38 & \multirow{3}{*}{0,38} & \multirow{3}{*}{$0,82^{*}$} \\
\hline & 31-38 yaş & 37 & 61,39 & & \\
\hline & $\begin{array}{l}39 \text { veya üzeri } \\
\text { yaş }\end{array}$ & 12 & 54,38 & & \\
\hline \multirow{3}{*}{$\begin{array}{l}\text { Öğretim stratejilerine } \\
\text { yönelik öz yeterlik }\end{array}$} & $23-30$ yaş & 69 & 60,55 & \multirow{3}{*}{1,64} & \multirow{3}{*}{$0,44^{*}$} \\
\hline & 31-38 yaş & 37 & 61,41 & & \\
\hline & $\begin{array}{l}39 \text { veya üzeri } \\
\text { yaş }\end{array}$ & 12 & 47,58 & & \\
\hline $\begin{array}{l}\text { Sınıf yönetimine yönelik } \\
\text { öz yeterlik }\end{array}$ & $23-30$ yaş & 69 & 58,96 & 2,10 & $0,34^{*}$ \\
\hline
\end{tabular}

Levene homojenlik testi sonucunda homojen çıkmayan veriler üzerinde Türkçeyi yabancı dil olarak öğretenlerin öz yeterlik algıları puanlarının yaş değişkenine göre anlamlı yönde farklılaşıp farklılaşmadığını anlamak için non-parametrik testlerden Kruskal Wallis H Testi kullanılmıştır. Tablo 2 
incelendiğinde ölçeğin üç alt boyutunda da yaş değişkenine göre anlamlı bir farklılı̆ın çıkmadığı görülmektedir. Elde edilen bu veriler, yaşın, Türkçeyi yabancı dil olarak öğretenlerin öz yeterlik algılarını aralarında farklılık oluşturacak kadar etkilemediğini göstermektedir.

"Türkçeyi yabancı dil olarak öğretenlerin öz yeterlik algıları mezun olunan lisans programına göre anlamlı düzeyde farklılaşmakta mıdır?" sorusuna ilişkin bulgular Tablo 3'te gösterilmektedir. Levene homojenlik testi sonucunda homojen çıkmayan veriler üzerinde Kruskal Wallis $\mathrm{H}$ Testi kullanılmıştır

Tablo 3. Türkçeyi Yabancı dil olarak öğretenlerin öz yeterlik ölçeği puanlarının mezun olunan lisans programı değişkenine göre Kruskal-Wallis H Testi sonuçları

\begin{tabular}{|c|c|c|c|c|c|c|}
\hline Faktörler & Gruplar & $\mathbf{N}$ & Sıra Ortalaması & KWH & $\mathbf{p}$ & $\begin{array}{c}\text { Farkın } \\
\text { Kaynağı }\end{array}$ \\
\hline \multirow{4}{*}{$\begin{array}{l}\text { Öğrenci katılımına yönelik } \\
\text { öz yeterlik }\end{array}$} & Türkçe Eğitimi & 55 & 62,70 & \multirow{4}{*}{3,994} & \multirow{4}{*}{ 262 } & \multirow{8}{*}{$\begin{array}{l}\text { Türkçe } \\
\text { Eğitimi } \\
\text {-Dilbilim }\end{array}$} \\
\hline & TDE & 45 & 60,90 & & & \\
\hline & Yabancı Diller & 9 & 53,06 & & & \\
\hline & Dilbilim & 9 & 39,39 & & & \\
\hline \multirow{4}{*}{$\begin{array}{l}\text { Öğretim stratejilerine } \\
\text { yönelik öz yeterlik }\end{array}$} & Türkçe Eğitimi & 55 & 67,24 & \multirow{4}{*}{8,602} & \multirow{4}{*}{, $035^{*}$} & \\
\hline & TDE & 45 & 57,30 & & & \\
\hline & Yabancı Diller & 9 & 47,17 & & & \\
\hline & Dilbilim & 9 & 35,56 & & & \\
\hline \multirow{4}{*}{$\begin{array}{l}\text { Sınıf yönetimine yönelik } \\
\text { öz yeterlik }\end{array}$} & Türkçe Eğitimi & 55 & 66,33 & \multirow{4}{*}{7,648} & \multirow{4}{*}{,054 } & \\
\hline & TDE & 45 & 58,40 & & & \\
\hline & Yabancı Diller & 9 & 46,11 & & & \\
\hline & Dilbilim & 9 & 36,67 & & & \\
\hline
\end{tabular}

${ }^{\bar{p}} \mathrm{p}<0,05$

Tablo 3’te ölçeğin öğrenci katılımına yönelik öz yeterlik ile sınıf yönetimine yönelik öz yeterlik alt boyutlarında mezun olunan lisans programına göre anlamlı bir farklığın olmadığı görülmektedir. Ancak ölçeğin öğretim stratejilerine yönelik öz yeterlik alt boyutunda Türkçe Eğitimi ile Dilbilim mezunları arasında Türkçe Eğitimi mezunları lehine anlamlı bir farklılığın olduğu görülmektedir.

"Türkçeyi yabancı dil olarak öğretenlerin öz yeterlik algıları öğrenim düzeyine göre anlamlı düzeyde farklılaşmakta mıdır?" sorusuna ilişkin bulgular Tablo 4'te gösterilmektedir.

Tablo 4. Türkçeyi yabancı dil olarak öğretenlerin öz yeterlik ölçeği puanlarının öğrenim düzeyi değişkenine göre Kruskal-Wallis H Testi sonuçları

\begin{tabular}{|c|c|c|c|c|c|c|}
\hline Faktörler & Gruplar & $\mathbf{N}$ & Sıra Ortalaması & KWH & $\mathbf{p}$ & Farkın Kaynağı \\
\hline \multirow{3}{*}{$\begin{array}{l}\text { Öğrenci katılımına } \\
\text { yönelik öz yeterlik }\end{array}$} & Lisans & 33 & 34,83 & \multirow{3}{*}{27,72} & \multirow{3}{*}{$0,00 *$} & \multirow{3}{*}{$\begin{array}{l}\text { Doktora-Lisans } \\
\text { Yüksek Lisans- } \\
\text { Lisans }\end{array}$} \\
\hline & Yüksek Lisans & 45 & 75,94 & & & \\
\hline & Doktora & 40 & 61,35 & & & \\
\hline \multirow{3}{*}{$\begin{array}{l}\text { Öğretim } \\
\text { stratejilerine } \\
\text { yönelik öz yeterlik }\end{array}$} & Lisans & 33 & 34,18 & \multirow{3}{*}{26,02} & \multirow{3}{*}{$0,00 *$} & \multirow{3}{*}{$\begin{array}{l}\text { Doktora-Lisans } \\
\text { Yüksek Lisans- } \\
\text { Lisans }\end{array}$} \\
\hline & Yüksek Lisans & 45 & 72,58 & & & \\
\hline & Doktora & 40 & 65,68 & & & \\
\hline \multirow{3}{*}{$\begin{array}{l}\text { Sınıf yönetimine } \\
\text { yönelik öz yeterlik }\end{array}$} & Lisans & 33 & 38,97 & \multirow{3}{*}{16,77} & \multirow{3}{*}{$0,00 *$} & \multirow{3}{*}{$\begin{array}{l}\text { Doktora-Lisans } \\
\text { Yüksek Lisans- } \\
\text { Lisans }\end{array}$} \\
\hline & Yüksek Lisans & 45 & 69,14 & & & \\
\hline & Doktora & 40 & 65,59 & & & \\
\hline
\end{tabular}

${ }^{*} p<0,05$ 
Levene homojenlik testi sonucunda homojen çıkmadığı için veriler üzerinde Kruskal Wallis $\mathrm{H}$ Testi kullanılmıştır Verilerin analizinde ölçeğin üç alt boyutunda da anlamlı farklılık bulunmuştur. Her üç alt boyutta da fark, doktora ile lisans düzeyi arasında doktora lehine ve yüksek lisans ile lisans düzeyi arasında yüksek lisans lehine çıkmıştır. Elde edilen bu veriler, Türkçeyi yabancı dil olarak öğretenlerin öz yeterlik algılarının yüksek olmasının onların öğrenim durumları ile ilişkili olduğunu göstermiştir.

"Türkçeyi yabancı dil olarak öğretenlerin öz yeterlik algıları deneyim süresine göre anlamlı düzeyde farkılaşmakta mıdır?” sorusuna ilişkin bulgular Tablo 5'te gösterilmektedir.

Tablo 5. Türkçeyi yabancı dil olarak öğretenlerin öz yeterlik ölçeği puanlarının deneyim süresi değişkenine göre Kruskal-Wallis H Testi sonuçları

\begin{tabular}{|c|c|c|c|c|c|c|}
\hline Faktörler & Gruplar & $\mathbf{N}$ & Sıra Ortalaması & KWH & $p$ & Farkın Kaynağı \\
\hline \multirow{3}{*}{$\begin{array}{l}\text { Öğrenci katılımına } \\
\text { yönelik öz yeterlik }\end{array}$} & $0-2$ yıl & 41 & 47,55 & \multirow{3}{*}{8,434} & \multirow{3}{*}{$0,01^{*}$} & \multirow{3}{*}{$\begin{array}{l}3-8 \text { yıl- } \\
0-2 \text { yıl }\end{array}$} \\
\hline & $3-8$ yll & 66 & 67,24 & & & \\
\hline & 9 yıl veya üzeri & 11 & 57,59 & & & \\
\hline \multirow{3}{*}{$\begin{array}{l}\text { Öğretim } \\
\text { stratejilerine yönelik } \\
\text { öz yeterlik }\end{array}$} & $0-2$ yıl & 41 & 45,63 & \multirow{3}{*}{$\begin{array}{c}10,58 \\
9\end{array}$} & \multirow{3}{*}{$0,00 *$} & \multirow{3}{*}{$\begin{array}{l}\text { 3-8 yıl- } \\
0-2 \text { yıl }\end{array}$} \\
\hline & $3-8$ yil & 66 & 67,66 & & & \\
\hline & 9 yıl veya üzeri & 11 & 62,23 & & & \\
\hline \multirow{3}{*}{$\begin{array}{l}\text { Sınıf yönetimine } \\
\text { yönelik öz yeterlik }\end{array}$} & $0-2$ yıl & 41 & 49,45 & \multirow{3}{*}{6,131} & \multirow{3}{*}{$0,04 *$} & \multirow{3}{*}{$\begin{array}{l}3-8 \text { yıl- } \\
0-2 \text { yıl }\end{array}$} \\
\hline & $3-8$ yıl & 66 & 66,17 & & & \\
\hline & 9 yıl veya üzeri & 11 & 56,91 & & & \\
\hline
\end{tabular}

${ }^{*} \mathrm{p}<0,05$

Tablo 5 incelendiğinde deneyim süresi değişkenin Türkçeyi yabancı dil olarak öğretenlerin öz yeterlik algılarını üç alt boyutta da anlamlı olarak etkilediği görülmektedir. Bu anlamlı farklılık üç alt boyutta da 3-8 yıl deneyim süresine sahip olanlar ile 0-2 yıl deneyim süresine sahip olanlar arasında 3-8 yıl deneyim süresine sahip olanlar lehinedir. Elde edilen bu veriler, orta düzeyde deneyime sahip olanların mesleğe yeni başlayanlara göre daha yüksek öz yeterlik algısına sahip olduğunu göstermektedir.

\section{Tartışma, Sonuç ve Öneriler}

Öz yeterlik algısı, Sosyal Bilişsel Öğrenme Kuramının, bireylerin öğrenme sürecini etkilediğini iddia ettiği en temel kavramların başında gelmektedir. Bu algı, insanların karar süreçlerini, duygusal, motivasyonel ve bilişsel işlevlerini düzenlemektedir (Bandura ve Locke, 2003). Öz yeterlik algısı, bireyin çeşitli görevleri gerçekleştirmeye ilişkin, kendi performansı hakkındaki algısıdır. Bireyin kendi hakkında oluşturduğu bu algının kaynağı ise çeşitli araştırmalarda, geçmiş deneyimler, başarı öyküsü, çevre ve psikolojik durumlar olarak belirtilmektedir (Bandura, 1982; Schunk, 1987). Bireylerin öz yeterlik algıları ile ilgili yapılan bu çalışmalar, öğretmen yetiştirme sürecine de yansıyarak daha etkili öğretmen yetiştirme programlarının yapılandırılmasına yön vermiştir. Öğretmenlerin öz yeterlik algıları; öğretimsel faaliyetleri düzenlemede ve yürütmede, öğrencilerin başarılarını artırmada ve 
onlara rehber olmada öğretmenlerin kendi performanslarına ilişkin yargılarıdır. Alan yazında öğretmen öz yeterlik algılarının performansta sağlanan başarı ile öğrencilerin sağladıkları başarı ile ilişkisinin olduğu belirtilmektedir (Bandura, 2003; Harrison, vd. 1997; Tschannen-Moran, Woolfolk Hoy ve Hoy, 1998). Bu çalışmada da, Türkçeyi yabancı dil olarak öğretenlerin öz yeterlik algılarının cinsiyet, yaş, mezun olunan lisans programı, öğrenim düzeyi ve deneyim süresi ile ilişkisi incelenmiştir.

Yabancılara Türkçe öğretimi alanına görülen talep, son yıllarda bu alanda görev yapan öğretmen sayısını da artırmıştır. Suriyeli Çocukların Türk Eğitim Sistemine Entegrasyonunun Desteklenmesi projesi ile Millî Eğitim Bakanlığının 2016-2017 yıllarında toplam 5.468 Türkçe öğreticisini istihdam etmesi ${ }^{1}$, Yunus Emre Enstitüsünün 43 ülkede kurduğu 54 Kültür Merkezinde Türkçe öğretimi faaliyetlerini sürdürmesi ${ }^{2}$ Türkçeyi yabancı dil olarak öğretenlerin sayısının gün geçtikçe arttı̆̆ını göstermektedir. Bu bakımdan Türkçeyi yabancı dil olarak öğretenlerin hem demografik yapısının hem de öz yeterlik algılarına ilişkin betimsel bulguların alan yazına ışık tutacağı öngörülmektedir.

Araştırmada elde edilen bulgular, Türkçeyi yabancı dil olarak öğretenlerin öz yeterlik algılarının cinsiyet değişkenine göre anlamlı düzeyde farklılaşmadığını göstermiştir. Elde edilen bulgular bazı çalışmalarla desteklenmektedir (Ekinci, 2013; Saracaloğlu, Karasakaloğlu ve Evin Gencel, 2010; Üstüner, Demirtaş, Cömert ve Özer,2009). Ancak bazı çalışmalarda kadınlar lehine (Şahin, Kurudayıoğlu, Tunçel ve Öztürk, 2013; Ülper ve Bağcı, 2012) ve erkekler lehine (Demirtaş, Cömert ve Özer, 2011; Korkut ve Babaoğlan 2012) anlamlı düzeyde farklılıklar da görülmektedir. Yaş değişkeninde de Türkçeyi yabancı dil olarak öğretenlerin öz yeterlik algılarının anlamlı oranda farklılık oluşturmadığı tespit edilmiştir. Elde edilen bulgular Çimen'in (2007) yaptığı çalışmanın bulgularıyla da örtüşmektedir. Bu doğrultuda daha sonraki araştırmalarda yaş ve cinsiyet değişkenini tespit etmede örneklemi oluşturan grupların Tipik Örnekleme Yöntemi ile seçilmesi önerilebilir.

Araştırmada Türkçeyi yabancı dil olarak öğretenlerin öz yeterlik algılarının, mezun olunan lisans programına göre anlamlı düzeyde farklılaştığı tespit edilmiştir. Bu anlamlı farklıık öğretim stratejilerine yönelik öz yeterlik boyutunda Türkçe Eğitimi mezunlarının Dilbilim mezunlarına göre daha yüksek öz yeterlik algısına sahip oldukları yönündedir. Elde edilen bu farklılık, Türkçe eğitimi mezunlarının lisans eğitimi boyunca eğitim psikolojisi, öğretim ilke ve yöntemleri, özel öğretim yöntemleri gibi dersleri almalarından kaynaklı olarak; öğretim stratejilerini uygulamaya yönelik öz yeterlik algılarının yüksek çıkmasını sağlayan bir etken olabilir. Çalışmadan elde edilen sonuçlardan hareketle, Türkçeyi yabancı dil olarak öğreten Dilbilim mezunlarına hizmet içi eğitimler verilebilir.

\footnotetext{
${ }^{1}$ https://pictes.meb.gov.tr/izleme/Faaliyetler/TurkceOgretimi\#

${ }^{2}$ www.yee.org.tr/sites/default/files/yayin/bulten_40_turkce.pdf
} 
Türkçeyi yabancı dil olarak öğreten Dilbilim mezunlarının eğitim öncesi ve sonrası öz yeterlik algılarındaki değişimler incelenebilir. Yabancı dil olarak Türkçe öğretimi yüksek lisans ve doktora programlarında öğrenim gören çeşitli branşlardan (Türk Dili ve Edebiyatı, Dilbilim, Çağdaş Türk Lehçeleri, Yabancı dil vs.) gelen bireyler dikkate alınarak yüksek lisans ve doktora ders içeriklerinde öğretim uygulamalarına yer verilebilir.

Araştırmada, Türkçeyi yabancı dil olarak öğretenlerin öz yeterlik algılarının öğrenim düzeyine göre anlamlı düzeyde farklılaştığı görülmüştür. Bu anlamlı farklılık öz yeterlik algısını oluşturan üç boyutta da doktora düzeyinin lisans mezunlarından, yüksek lisans düzeyinin lisans mezunlarından daha yüksek öz yeterlik algısına sahip oldukları yönündedir. Elde edilen bu veriler, öğrenim düzeyinin yüksek olmasının Türkçeyi yabancı dil olarak öğretenlerin öz yeterlik algılarına olumlu yönde etki ettiğini göstermiştir. Bu doğrultuda yabancı dil olarak Türkçe öğretiminin istihdam sürecinde, öğrenim düzeyi kriterinin önemsenmesi gerektiği söylenebilir. Yüksek lisans ve doktora öğrenimi düzeyinde bulunanların öz yeterlik algıları ile akademik başarıları arasındaki ilişki incelenebilir.

Araştırmada Türkçeyi yabancı dil olarak öğretenlerin öz yeterlik algıları deneyim süresine göre incelendiğinde, öz yeterlik algılarının deneyim süresine göre anlamlı düzeyde farklılaştığı sonucuna varılmıştır. Bu anlamlı farklılık öz yeterlik algısını oluşturan üç boyutta da 3-8 yıl arasında deneyim sahibi olanların, 0-2 yıl arasında deneyim sahibi olanlara göre daha yüksek öz yeterlik algısına sahip olduğu yönündedir. Buna benzer olarak Saracaloğlu, Karasakaloğlu ve Evin Gencel (2010), Türkçe öğretmenlerinin öz yeterlik algılarının meslekteki kıdemlerine göre anlamlı düzeyde farklılaştığını tespit etmişlerdir. Bu bulgular, orta seviyede deneyim sahibi olanların mesleğe yeni başlayanlara göre daha yüksek öz yeterlik algılarına sahip olduklarını göstermektedir. Elde edilen bu sonuçlardan hareketle mesleğe yeni başlayan öğreticiler, hizmet içi eğitimlerle desteklenebilir. Gelecekteki çalışmalarda Türkçeyi yabancı dil olarak öğretenlerin mesleki kıdemleri, öz yeterlik algıları ve tükenmişlik duyguları arasındaki korelasyon incelenebilir. Genel olarak ise Türkçeyi yabancı dil olarak öğretenlerin öğretim hizmeti verilen öğrenci grupları ile öz yeterlik algıları arasındaki ilişki incelenerek alana katkı sunulabilir.

\section{Kaynaklar}

Alyılmaz, C. (2010). Türkçe öğretiminin sorunları. Turkish Studies, 5(3), 728-749.

Bandura, A. (1965). Influence of models' reinforcement contingencies on the acquisition of imitative responses. Journal of Personality and Social Psychology, 1(6), 589-595.

Bandura, A. (1982). Self efficacy mechanism in human agency. American psychologist, 37(2), 122-147.

Bandura, A. (1999). Social cognitive theory: An agentic perspective. Asian Journal of Social Psychology, 2, 21-41.

Bandura, A. (2001). Social cognitive theory of mass communication. Media Psychology, 3(3), 265-299.

Bandura, A. and Huston, A. C. (1961). Identification as a process of incidental learning. The Journal of Abnormal and Social Psychology, 63(2), 311-318. 
Bandura, A., Ross, D. and Ross, S. A. (1963). Imitation of film-mediated aggressive models. The Journal of Abnormal and Social Psychology, 66(1), 3-11.

Bandura, A., Barbaranelli, C., Caprara, G. V. and Pastorelli, C. (2001). Self-efficacy beliefs as shapers of children's aspirations and career trajectories. Child Development, 72(1), 187-206.

Bandura, A. and Locke, E. A. (2003). Negative self-efficacy and goal effects revisited. Journal of Applied Psychology, 88(1), 87-99.

Barın, E. (Nisan, 2010). Yabancılara Türkçe öğretiminde öğretmen yeterliği ve yardımcı öğretmen kavramı. II. Uluslararası Türk Dünyası Kültür Kongresi, İzmir. Erişim Adresi: www. Turkcede.org/yeni-ogrenenlereturkce-ogretimi/194-yabancilara-turkce-ogretiminde-ogretmen-yeterligi-ve-yardimci-ogretmenkavrami.html

Barın, E., Çangal, Ö. ve Başar, U. (2017). Yabancı dil olarak Türkçe öğretimi alanında göre yapacak öğretmenlerin özel alan yeterliklerine ilişkin bir öneri. International Journal of Language Academy, 5(7), 81-98.

Büyüköztürk, Ş., Kılıç-Çakmak, E., Akgün, Ö. E., Karadeniz, Ş. ve Demirel, M. (2014). Bilimsel araştırma yöntemleri (17. Baskı). Ankara: Pegem Akademi.

Çapa, Y., Çakıroğlu J. ve Sarıkaya, H. (2005). Öğretmen özyeterlik ölçeği Türkçe uyarlamasının geçerlik ve güvenirlik çalışması. Eğitim ve Bilim, 30(137), 74-81.

Çimen, S. (2007). Illköğretim öğretmenlerinin tükenmişlik yaşantıları ve yeterlik algıları. Yayımlanmamış Yüksek Lisans Tezi, Kocaeli Üniversitesi, Kocaeli.

Ekinci, H. (2013). Öğretmen adaylarının özyeterlik algıları: Müzik, resim ve beden eğitimi. Turkish Studies, 8(3), 189-196.

Ekiz, D. (2013). Bilimsel araştırma yöntemleri (3. Baskı). Ankara: Anı Yayıncılık.

Demirtaş, H., Cömert M. ve Özer, N. (2011). Öğretmen adaylarının özyeterlik inançları ve öğretmenlik mesleğine ilişkin tutumları. Eğitim ve Bilim, 36(159), 96-111.

Fackler, S. and Malmberg, L. E. (2016). Teachers' self-efficacy in 14 OECD countries: Teacher, student group, school and leadership effect. Teaching and teacher education, 56, 185-195.

Harrison,A. W., Rainer, R. K., Hochwarter W. A. and Thompson K. R. (1997). Testing the self-efficacyperformance linkage of social-cognitive theory. The Journal of Social Psychology, 137(1), 79-87.

Karababa, Z. C. (2009). Yabancı dil olarak Türkçenin öğretimi ve karşılaşılan sorunlar. Ankara Üniversitesi Eğitim Bilimleri Fakültesi Dergisi, 42(2), 265-277.

Kavrayıcı, C. ve Bayrak, C. (2016). Öğretmen adaylarının öz-yeterlik algıları. Adıyaman Üniversitesi Sosyal Bilimler Enstitüsü Dergisi, 8(23), 623-658.

Korkut, K. ve Babaoğlan, E. (2012). Sınıf öğretmenlerinin öz yeterlik inançları. Uluslararası Yönetim iktisat ve işletme Dergisi, 8(16), 269-282.

Mete, F. (2012). Türkçeyi yabancı dil olarak öğreten öğretmenlerin özel alan yeterlikleri üzerine bir araştırma. Yayımlanmamış Doktora Tezi, Gazi Üniversitesi, Ankara.

Mete, F. ve Gürsoy, Ü. (2013). Yabancı dil olarak Türkçe öğretiminde öğretmen yeterliklerine ilişkin görüşler. Hacettepe Üniversitesi Eğitim Fakültesi Dergisi, 28(3), 343-356.

Özdemir, E. (2015). Tarama yöntemi. M. Metin (Ed.), Kuramdan uygulamaya eğitimde bilimsel araştırma yöntemleri (2. Baskı) içinde (77-97). Ankara: Pegem Akademi.

Saracaloğlu, A.S., Karasakaloğlu, N. ve Evin Gencel, í. (2010). Türkçe öğretmenlerinin özyeterlik düzeylerinin çeşitli değişkenlere göre incelenmesi. Elektronik Sosyal Bilimler Dergisi, 9(3), 265-283.

Şahin, Ç., Kurudayıoğlu, M., Tunçel, H. ve Öztürk, Y. A. (2013). Türkçe öğretmeni adaylarının lisans düzeyinde verilen yabancılara Türkçe öğretimi (YTÖ) dersine yönelik özyeterlik algıları. Ana Dili Eğitimi Dergisi, 1(2), 36-45. 
Şengül, K. (Haziran, 2015). Yabancı dil olarak Türkçe öğretimi yapanların özel alan yeterlikleri üzerine. EJER Kongresi Eğitimde Inovasyon ve Profesyonelleşme, Ankara. Erişim Adresi: ejercongress.org/pdf/BildiriKitabı2015.pdf. (Sayfa No: 364-370).

T.C. Kalkınma Bakanlığı (2015). Yükseköğretimin uluslararasılaşması çerçevesinde Türk üniversitelerinin uluslararası öğrenciler için çekim merkezi haline getirilmesi. Ankara: Kalkınma Araştırma Merkezi, Yayın No: 2936.

Tschannen-Moran M. and Woolfolk Hoy, A. (2001). Teacher efficacy: Capturing an elusive construct. Teaching and Teacher Education, 17, 783-805.

Ülper, H. ve Bağcı, H. (2012). Türkçe öğretmeni adaylarının öğretmenlik mesleğine dönük öz yeterlik algıları. Turkish Studies, 7(2), 1115-1131.

Üstün, A. ve Tekin, S. (2009). Amasya eğitim fakültesindeki öğretmen adaylarının özyeterlilik inançlarının çeşitli değişkenler açısından karşılaştırılması. Abant Izzet Baysal Üniversitesi Eğitim Fakültesi Dergisi, 9(1), 3547.

Üstüner, M., Demirtaş, H., Cömert M. ve Özer, N. (2009). Ortaöğretim öğretmenlerinin öz-yeterlik algıları. Mehmet Akif Ersoy Üniversitesi Eğitim Fakültesi Dergisi, 9(17), 1-16.

Yaylı, D. ve Kitiş Çınar, E. (2015). Hizmet öncesi Türkçe öğretmenlerinin özyeterlik inançları üzerine boylamsal bir çalışma. Dil Eğitimi ve Araştırmaları Dergisi, 1(2), 35-4.

Yıldız, Ü. ve Tepeli, Y. (2014). Yabancı dil olarak Türkçe öğretiminde öğretmen yeterlikleri üzerine bir çalışma. International Journal of Language Academy, 2(4), 564-578.

Yoo, J. H. (2016), The effect of professional development on teacher efficacy and teachers' self-analysis of their efficacy change. Journal of Teacher Education for Sustainability,18(1), 84-94.

\section{Extended Abstract}

Introduction

Teachers' self-perception that they can deal with the tasks in the teaching process is called selfefficacy. In particular, the self-efficacy perceptions of prospective teachers (Ekinci, 2013, Demirtaş, Cömert and Özer, 2011, Şahin, Kurudayıoğlu, Tunçel and Öztürk, 2013, Yaylı and Kitiş Çınar, 2015, Ülper ve Bağcı, 2012) and in-service teachers (Korkut and Babaoğlan 2012; Saracaloglu, Karasakaloglu, Evin Gencel, 2010; Üstüner, Demirtaş, Cömert and Özer, 2009) have been investigated and the findings have been discussed. It is only recently that research on the qualifications and self-efficacy perceptions of teachers who teach Turkish as a foreign language has started. According to the data by the Ministry of Development (2015) the number of foreign students coming to Turkey has increased annually since 2003. This has also led to an increase in the number of organizations that teach Turkish as a foreign language. Hence, in teaching Turkish as a foreign language, studies on teacher competencies seems to increase.

The purpose of this research is to examine the self-efficacy perceptions of teachers who teach Turkish as a foreign language in terms of gender, age, undergraduate major, level of education and experience. For this purpose, the following questions were formulated in the study.

1- Do the self-efficacy perceptions of teachers who teach Turkish as a foreign language differ at a significant level in terms of their genders?

2- Do the self-efficacy perceptions of teachers who teach Turkish as a foreign language display a significant difference in terms of their ages?

3- Do the self-efficacy perceptions of teachers who teach Turkish as a foreign language show a significant difference in terms of their undergraduate majors?

4- Do the self-efficacy perceptions of teachers who teach Turkish as a foreign language differ significantly in terms of their level of education?

5- Do the self-efficacy perceptions of teachers who teach Turkish as a foreign language differ significantly in terms of professional experience?

\section{Method}

Cross-sectional survey method was used in the study. 118 teachers who taught Turkish as a foreign language in various educational institutions in Turkey participated in the study. As data collection tools, the "Teacher Self-efficacy Scale" developed by Tschannen-Moran and Woolfolk Hoy (2001) and adapted by Çapı, 
Çakıroğlu and Sarıkaya (2005) and a "personal information form" were used. In the analysis of the data frequency, percentage, Independent Groups t-Test and Kruskal-Wallis Tests were used.

\section{Result and Discussion}

Findings showed that the self-efficacy perceptions of teachers who teach Turkish as a foreign language did not differ significantly in terms of gender. This finding is also supported by some studies (Ekinci, 2013, Saracaloglu, Karasakaloglu and Evin Gencel, 2010, Üstüner, Demirtaş, Cömert and Özer, 2009). However, in some studies, significant differences exist, favoring women (Şahin, Kurudayıoğlu, Tunçel and Öztürk, 2013; Ülper ve Bağcl, 2012) and in some, favoring men (Demirtaş, Cömert and Özer, 2011, Korkut and Babaoğlan 2012). It has been determined that the self-efficacy perceptions of those who teach Turkish as a foreign language do not differ significantly in terms of age. The findings obtained are also consistent with the findings of Çimen (2007).

In the study, it has been determined that the self-efficacy perceptions of teachers who teach Turkish as a foreign language differ significantly in terms of their undergraduate majors. This difference suggests that Turkish teacher education major graduates have a higher self-efficacy perception than graduates of other majors in the dimension of self-efficacy towards instructional strategies. This difference is due to the fact that graduates of Turkish teacher education take courses such as educational psychology, teaching principles and methods, and special teaching methods during their undergraduate education; this may be a factor that provides a high self-efficacy perception in applying teaching strategies. According to the results obtained, inservice training may be provided for teachers who are graduates of other majors. Research may be done to capture the changes in those teachers' in self-efficacy perceptions before and after such training.

In the study, it was seen that the self-efficacy perceptions of teachers teaching Turkish as a foreign language differed significantly in terms of their level of education. Teachers who hold a doctoral degree have higher self-efficacy perceptions than others. The obtained data show that the high level of education has a positive effect on the self-efficacy perceptions of teachers who Turkish as a foreign language. In this respect, it can be said that the education level criterion should be given importance in the process of employing teachers who will teach Turkish as a foreign language.

When the self-efficacy perceptions of teachers who teach Turkish as a foreign language were examined in terms of the length of professional experience, it was concluded that teachers' self-efficacy perceptions differed significantly in terms of that variable. This significant difference suggests that those who have 3-8 years of experience in the three dimensions have higher self-efficacy perceptions than those who have professional experience of 0-2 years. Similarly, Saracaloglu, Karasakaloglu and Evin Gencel (2010) found that Turkish teachers' self-efficacy perceptions differed significantly in relation to their seniority in the profession. These findings show that those with moderate experience have higher self-efficacy perceptions than those who are new to the profession. 